\title{
Intraocular foreign bodies
}

\author{
Kunyong Xu MD MHSc, David R.P. Almeida MD MBA PhD
}

Cite as: CMAJ 2017 January 30;189:E163. doi: 10.1503/cmaj.160428

\section{1 \\ 2}

\section{Risk of intraocular foreign body is associated with mechanism of injury}

Accurate history-taking that involves attention to the mechanism of ocular injury should be obtained. High-risk mechanisms for intraocular foreign bodies include grinding, hammering, metal shaving, machine yard work and exposure to explosives. ${ }^{1}$ Ophthalmic examination should include dilation of the pupil

In $21 \%-38 \%$ of cases, intraocular foreign bodies are located in the anterior segment, allowing identification with slit-lamp examination alone. ${ }^{1}$ (Figure 1A) However, most intraocular foreign bodies are located in the posterior segment and require a dilated-pupil examination. ${ }^{1}$

Imaging should be conducted promptly to diagnose and

localize intraocular foreign bodies

Immediate computed tomography (CT) of the orbits without contrast is the modality of choice in suspected cases (Figure 1B). ${ }^{1}$ Both 1- and 3-mm cuts on CT have $100 \%$ sensitivity for detecting metallic, glass and stone intraocular foreign bodies of $0.5 \mathrm{~mm}$ in diameter. ${ }^{2}$ Plain-film radiography is inferior to $\mathrm{CT}$, because it may miss nonmetallic intraocular foreign bodies up to $60 \%$ of the time. $^{1}$

\section{Antibiotics should be prescribed early to prevent \\ endophthalmitis}

Endophthalmitis is a complication in 3\%-30\% of cases involving intraocular foreign bodies. ${ }^{1}$ Therefore, patients with this injury should be given immediate treatment with prophylactic antibiotics. Systemic administration (intravenously or orally) of fluoroquinolones are good options because of their superior intraocular penetration. ${ }^{3}$

\section{5}

\section{Patients with an intraocular foreign body require urgent} referral to an ophthalmologist

The injured eye(s) should be protected with a rigid eye shield, and the patient should not receive anything by mouth during urgent transport to an ophthalmologist. Primary surgery to close the entry site(s) should be performed by an ophthalmologist within 12 hours after injury to reduce the risk of endophthalmitis and to prevent intraocular content extrusion. ${ }^{4}$ The foreign body must be removed; however, there is disagreement about the time frame for removal. ${ }^{5}$

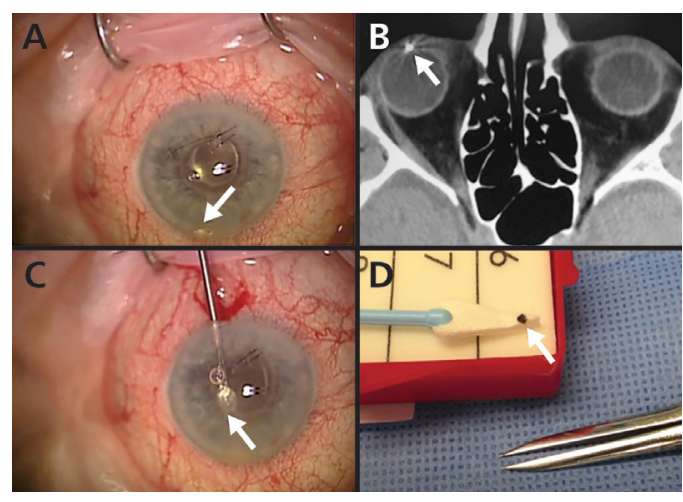

Figure 1: Intraocular metallic foreign body embedded in the anterior chamber of the right eye. (A) Metallic foreign body in the anterior chamber (arrow). (B) Axial computed tomography scan of the orbits showing a well-defined, hyperdense foreign body producing streak artifacts in the anterior chamber (arrow). (C) Surgical removal of the foreign body (arrow). (D) The foreign body removed from the eye (arrow).

\section{References}

1. Parke DW III, Flynn HW Jr, Fisher YL. Management of intraocular foreign bodies: a clinical flight plan. Can J Ophthalmol 2013;48:8-12

2. Dass AB, Ferrone PJ, Chu YR, et al. Sensitivity of spiral computed tomography scanning for detecting intraocular foreign bodies. Ophthalmology 2001;108:2326-8.

3. Hariprasad SM, Shah GK, Mieler WF, et al. Vitreous and aqueous penetration of orally administered moxifloxacin in humans. Arch Ophthalmol 2006;124:178-82.

4. Essex RW, Yi Q, Charles PG, et al. Post-traumatic endopthalmitis. Ophthalmology 2004;111:2015-22.

5. Thompson WS, Rubsamen PE, Flynn HW Jr, et al. Endophthalmitis after penetrating trauma: risk factors and visual acuity outcomes. Ophthalmology 1995;102:1696-701.

\section{Competing interests: None declared.}

This article has been peer reviewed.
Affiliations: Department of Ophthalmology (Xu), Queen's University, Kingston, Ont.; VitreoRetinal Surgery PA (Almeida), Minneapolis, Minn.
Acknowledgement: The authors thank John B. Davies for providing the figures.

Correspondence to: David Almeida, dalmeida@evolation-medical.com 